\title{
PESQUISA E INOVAÇÃO: novos desafios para a educação superior no Brasil e na Alemanha
}

\author{
Clarissa Eckert Baeta Neves* \\ Fabrício Monteiro Neves ${ }^{* *}$
}

\begin{abstract}
O artigo analisa a dinâmica de transformações institucionais por que passam as universidades no Brasil e na Alemanha para que assumam papéis estratégicos em um contexto social, político e econômico caracterizado pela dinâmica da inovação. Reformas do sistema de ensino superior, tanto quanto projetos e estratégias institucionais são objetos de análise no trabalho. A Alemanha vem passando por um processo intenso de reforma do ensino superior com a implantação do projeto de Bolonha, no campo de produção da pesquisa científica e tecnológica e na relação com o mercado, com a implantacão de vigorosos projetos de fomento e de direção da pesquisa acadêmica nacional. No Brasil, há enormes resistências históricas às mudanças. Predomina, ainda, um modelo de ensino superior pouco diversificado e com baixa relação com a indústria e o mercado, embora nos últimos anos tenham se multiplicado as iniciativas de apoio às transformações. Reformas sistêmicas e institucionais são analisadas à luz das peculiaridades históricas e sociais das relações entre universidade e sociedade nos dois países, focalizando dinâmicas mais contemporâneas.

PALAVRAS-CHAVE: pesquisa e inovação, universidade, conhecimento, reforma, políticas.
\end{abstract}

\section{INTRODUÇÃO}

No início do século XXI, uma nova agenda temática se coloca para o desenvolvimento científico e tecnológico. Problemas como a garantia de alimentos para a crescente população mundial, a produção de energia e as mudanças climáticas desafiam formas mais tradicionais de resolução e fazem surgir novos arranjos institucionais, transformando as dinâmicas relacionais do sistema universitário com a economia, o estado, a empresa (Gibbons et al., 1994; Etzkowitz, 2003).

Nesse cenário de mudanças constantes e drásticas, a sociedade tem ressaltado, cada vez mais, a importância de ciência, tecnologia e inovação (C,T\&I) para a promoção do desenvolvimento. Isso está explícito na comunicação dos mais distintos sistemas sociais, como a economia, a políti-

\footnotetext{
* Doutora em Sociologia pela Universidade de MünsterAlemanha. Professora da Universidade Federal do Rio Grande do Sul. Pesquisadora CNPq. Coordenadora do Grupo de Estudos sobre Universidade/GEU/UFRGS. Av. Bento Gonçalves 9500. Cep: 91509900 Porto Alegre -
Rio Grande do Sul - Brasil. clarissa.neves@yahoo.com.br

** Doutor em Sociologia. Professor da Universidade Federal de Santa Maria. fabriciomneves@gmail.com
}

ca e a educação, ao ressaltarem que tais elementos pautam seus processos, como o da competição econômica entre países, da política científica, tecnológica e da inovação e das formas assumidas pela universidade para a promoção da inovação. ${ }^{1}$

Em todos os países, os sistemas de pesquisa e inovação se fortalecem e se dinamizam. Isso pode ser visto pelo aumento considerável dos gastos globais em pesquisa e desenvolvimento (P\&D) que, desde o final da década de 1990, duplicaram. Atualmente, trabalham em P\&D mais de 5,7 milhões de pessoas. Os países desenvolvidos, mas também os emergentes estão investindo cada vez mais em educação, pesquisa e inovação. A corrida pelo conhecimento vem se intensificando, bem como a competição por tecnologia e inovação, posto que as novas demandas da sociedade global vêm exigindo novos conhecimentos (BMBF, 2010).

Neste contexto, o conceito de inovação ganhou nova formulação e abrangência, extrapolando

${ }^{1}$ Deve-se ter claro que os problemas assinalados acima são produtos também da própria dinâmica científica e tecnológica (ver Beck, 2010), o que permite afirmar que, também, C,T\&I são parte do problema, como resultados não esperados da dinâmica econômica. 
o âmbito da estrita transformação de conhecimento em valor econômico. Na nova acepção, inovação é a transformação de conhecimento numa aplicação capaz de gerar soluções para problemas concretos na economia, na sociedade, na política, com perspectiva de ganhos econômicos privados ou de ganhos na concepção e nos resultados da prestação de serviços de interesse e caráter públicos.

Diferentes definições de inovação têm sido apresentadas na literatura. No Relatório do Global Innovation Index (GII) de 2011, ${ }^{2}$ inovação é definida como a implementação de um novo produto ou um produto melhorado significativamente (bens ou serviços), um novo processo, um novo método de marketing, ou um novo método organizacional em práticas empresariais, organização dos lugares de trabalho ou relações externas (GII, 2011; Dutta; Benavente, 2011 p.4).

A evolução do conceito de inovação pode ser referida às diferentes versões do Manual de Oslo (OECD/EC, 2005), um guia para estatísticos em seus esforços recentes para medir a inovação. Nas suas primeiras edições 1992 e 1997, o Manual focava exclusivamente inovações tecnológicas e abrangia apenas produtos e processos. A ruptura deu-se após 1997, quando foi expandida a abrangência conceitual, de indústrias manufatureiras para serviços. A edição de 2005 incorporou três desenvolvimentos cruciais: primeiro, o qualificativo tecnológico foi eliminado; segundo, foram adicionadas inovações em métodos e; terceiro, pela primeira vez, o setor público foi mencionado como uma área que deveria merecer mais atenção (OECD/ EC, 2005; GII, 2011). ${ }^{3}$

Segundo o relatório GII, uma inovação pode ser nova para um setor ou mercado, ou nova para

${ }^{2} \mathrm{O}$ projeto de construção de um Índice Global de Inovação (GII) foi lançado pela INSEAD (The International Business School) em 2007, com o objetivo de determinar métricas e abordagens que melhor captassem a riqueza de inovação na sociedade e de ir além de medidas tradicionais de inovação, como o número de doutores, o número de artigos de pesquisa produzidos, as patentes concedidas, os centros de pesquisa criados, e pesquisa e desenvolvimento (R \& D) ( GII, 2011).

${ }^{3}$ Em 2010, o relatório ministerial da OCDE - Inovações Estratégicas - propõe ampliar a metodologia para captar a inovação no setor público e inovações sociais que correspondam à realidade da inovação dos dias atuais (OCDE, 2010b). um agente. Também pode ser disruptiva, em que o foco é no impacto, em vez de na novidade. Inovação também ocorre quando uma empresa introduz um produto ou processo pela primeira vez em um país. Ela ocorre, ainda, quando outras empresas imitam a empresa pioneira. Além disso, ocorre quando a primeira firma e suas seguidoras fazem pequenas melhorias e adaptações para melhorar um produto ou um processo de produção, levando a melhorias de produtividade (Dutta; Benavente, 2011, p.4). Inovações também não estão restritas às empresas. São originárias de todos os agentes da sociedade: no nível da empresa, ou de uma indústria, em serviços governamentais ou no setor público, na academia, em uma cooperativa e na sociedade em geral. As atividades de inovação por esses agentes são geralmente complementares: protótipos podem ser desenvolvidos em um laboratório de pesquisa da universidade, e o produto final introduzido no mercado por uma empresa (OECD, 2010a). ${ }^{4}$

Em função de a inovação ser uma informação inserida no processo de reprodução dos sistemas sociais, como veremos no tópico 2, cada vez mais se espera que os resultados de tais processos, sejam educativos, tecnológicos e científicos, possam ser transformados em inovações para a sociedade e para o mercado. Cabe distinguir esses dois âmbitos.

A inovação para a sociedade, como resultado de pesquisa científica e tecnológica, agrega valor social e pode ser exemplificada nas mudanças para a melhoria do sistema escolar (políticas educacionais), nas melhorias do sistema de trânsito (políticas de trânsito), na saúde (melhorias no atendimento), etc. Uma inovação é social na medida em que é transmitida e é aceita e difundida ampla-

${ }^{4}$ Segundo o GII (2011), um desafio-chave é encontrar metodologias que capturem a inovação como acontece hoje, particularmente em mercados emergentes. A definição de inovação, assim, tem se ampliado e, com ela, o desafio para a coleta de dados, porque inovações não estão mais restritas a laboratórios de $\mathrm{P} \& \mathrm{D}$ e à publicação de trabalhos científicos. Os indicadores de inovação estão divididos por indicadores de input, como os institucionais, pesquisa e capital humano, infraestrutura, sofisticação de mercado e sofisticação de negócios e indicadores de output, como resultados científicos e resultados criativos (Dutta; Benavente, 2011, p.9) 
Clarissa Eckert Baeta Neves, Fabrício Monteiro Neves

mente por toda a sociedade ou em certos sistemas dela, sem o interesse do lucro, para ser, finalmente, institucionalizada como prática social nova ou tornada rotina (Howaldt; Schwarz, 2010). Pesquisa e inovação voltadas para o equacionamento de problemas sociais dependem de um diálogo entre os atores envolvidos (universidades, institutos de pesquisa) e a realidade concreta. Especialmente com relação às controvérsias sociais sobre novas tecnologias e aos desafios a serem solucionados, é necessário um dialogo multi e transdisciplinar, ao mesmo tempo em que se deve levar em conta a perspectiva dos diversos atores impactados com as transformações inexoráveis.

A inovação para o mercado, a partir dos resultados de pesquisa científica, tem por finalidade a transformação do conhecimento em valor econômico. Aqui, é fundamental que ocorra uma maior interação entre as universidades, as instituições de pesquisa e as empresas, através de pesquisa, desenvolvimento e transferência de conhecimento e tecnologia. Novas formas de cooperação podem ser observadas, assim como novas legislações, modelos de parceria do setor público com o setor privado, redes de cooperação, etc. É preciso, no entanto, mencionar também a inovação para o mercado realizada diretamente pelas empresas e que tem por finalidade imediata a transformação do conhecimento em produto com valor econômico e em ganhos de competitividade. Nesse quesito, talvez resida a maior diferença entre Brasil e Alemanha no que se refere a participação da universidade no sistema de inovação, como se verá adiante.

Reconhece-se, portanto, a complexidade que envolve o conceito de inovação. O maior ou menor sucesso, nesse campo, está condicionado a inúmeros fatores: ambiente favorável à educação, ao domínio de conhecimentos em escala ampliada socialmente, de competição e de estímulos à iniciativa individual e ao trabalho interdisciplinar em redes. Corresponde, portanto, a um estágio complexo e altamente flexível de coexistência dos distintos sistemas sociais.

O relatório sobre inovação do Global Innovation Index (GII, 2011) parte dessa mesma linha de argumentação. Sua análise dos indicadores de input revela a percepção de que inovação, como processo, resulta de uma combinação virtuosa de fatores que expressam um grau elevado de sofisticação - diferenciação social - do sistema social em questão. É possível, então, afirmar que terão mais sucesso no sentido de estimular a inovação, as políticas e programas que sejam capazes de conformar o ambiente, impregnando-o das características apontadas acima, fomentando aquilo que ficou conhecido como sistema nacional de inovação (Etzkowitz; Leydesdorff, 2000).

Nessa linha de raciocínio, o presente artigo pretende discutir as transformações que vêm ocorrendo no âmbito da educação superior, como respostas do sistema educativo e da ciência à construção de um sistema nacional de inovação, em duas realidades distintas: a alemã e a brasileira. Pretende-se descrever as políticas e programas desenvolvidos em cada país com vistas ao incremento de suas respectivas capacidades de inovação, com ênfase nas políticas educacionais e de C\&T\&I implementadas nesses contextos. Essas duas realidades têm em comum os recentes esforços de elaboração de propostas com vistas à modernização e à dinamização do sistema de ensino superior e da pesquisa. No caso da Alemanha, o trabalho foca a experiência de reforma do ensino superior após o processo de Bolonha e analisa as principais políticas implementadas a partir de 2005 para fomentar a pesquisa e a inovação. No caso do Brasil, expõemse programas com foco na inovação que vêm produzindo mudanças no ensino superior e no fomento das atividades de pesquisa e inovação, como o REUNI, a lei da Inovação e a Lei do Bem.

Para analisar as novas configurações ou diferenciações no ensino superior e na pesquisa e inovação, propomos a abordagem da teoria dos sistemas. Tomar a sociedade moderna como uma sociedade mundial formada por sistemas funcionais permite uma melhor compreensão dos processos de mudança social. O trabalho se vale, também, do argumento de que uma diferenciação entre centro e periferia é possível no plano da sociedade global e no caso específico do sistema mundial de CT\&I. 
A partir disso, pode-se falar em modernidade periférica em relação a uma modernidade central no tratamento de sistemas organizados, em oposição à dicotomia entre tradicional e moderno. Isto nos dará, finalmente, elementos teóricos para localizar as realidades nacionais analisadas em seu estágio de desenvolvimento de C,T\&I.

\section{A PRODUÇÃO DA PESQUISA E INOVAÇÃO: uma leitura sistêmica}

Para compreender o processo de inovação e o papel da universidade nesse processo, faremos uma leitura nos termos da teoria dos sistemas sociais, especificamente aquela relacionada aos trabalhos do sociólogo alemão Niklas Luhmann. Focalizaremos em três questões teóricas específicas que nos auxiliarão na compreensão da inovação e do papel da universidade nesse processo. A primeira diz respeito à reprodução dos sistemas sociais; a segunda focaliza os diversos mecanismos de relação entre eles e, finalmente, a consequência desse processo para a formação do contexto sistêmico significativo para o processo mais geral de inovação, atentando para a formação de regimes centrais e periféricos de reprodução sistêmica.

Para Luhmann (1998), sistema social é sistema de comunicação processador de sentido, contextos que transformam ruídos externos ou internos - perturbações de outros sistemas - em informações significativas, disponibilizadas agora em sua rede de autorreprodução, mediante seleção. Porém decorre desse processo o aumento da complexidade interna do sistema, levando-o a reagir, por sua vez, a ela. Nesse particular, o sentido global do sistema é reintroduzido em formas, subsistemas que adquirem autonomia relativa em relação ao sistema do qual se diferenciaram. Sentido global é entendido como a diretriz condutora das comunicações possíveis, códigos binários que canalizam comunicações significativas (Luhmann, 2007). ${ }^{5}$ Desse modo

${ }^{5}$ Luhmann (1996) discute os códigos binários com base na teoria de Talcott Parsons a respeito dos meios de comunicação simbolicamente generalizados: poder, dinheiro, verdade, entre outros. Para Luhmann, tais códigos é que se diz que todo ruído externo só penetra na comunicação de um sistema específico satisfazendo suas próprias condições internas.

Pode-se observar a complexificação da ciência através da fragmentação disciplinar, temática e metodológica. Tal processo resulta em instâncias internas de promoção de simplificações, como a especialização temática e técnica, que são construídas por meio do sentido. A complexificação dá-se também no nível organizacional, com a diferenciação da ciência em centros, institutos e grupos de pesquisa. A complexificação de âmbitos processadores de sentido na sociedade moderna disponibiliza uma gama imensa de possibilidades de ação e vivência nos sistemas sociais, que, caso efetivadas, podem significar inovações sistêmicas e organizacionais (Stichweh, 2000).

Esse processo de autoconstrução sistêmica, de novação por meio dos limites de sentido, acarreta necessariamente processos de generalização simbólica, ou seja, os acontecimentos do entorno, as condições disponíveis aos sistemas desde fora, apresentar-se-ão de uma maneira generalizada no processo de reprodução sistêmica por meio de suas comunicações. O elemento do entorno, agora generalizado, é pleno de sentido porque foi incorporado ao sistema e, agora, pode contribuir para a reprodução de seus distintos elementos. Ademais, a reprodução do sistema, ao apresentar uma dimensão temporal, leva as generalizações a manifestarem um alto grau de independência em relação às condições anteriores que a geraram. Ainda que se vinculem ao sentido específico fixado no tempo, elas estarão sempre sujeitas às condições a posteriori, portanto, passíveis de serem modificadas, inovadas.

As generalizações simbólicas significativas apresentam outras características fundamentais para o sistema, se forem analisadas em correspondência com a estrutura de expectativas, as quais também são formadas no intercurso sistêmico de diminuição de complexidade por meio da seleção

são poder e não poder, ter e não ter, verdade e não verdade, e assim por diante. Cada um corresponderá ao lado interno e externo de um dado sistema social, a saber, poder para a política, ter para a economia, fé para a religião, verdade para a ciência e assim por diante. 
Clarissa Eckert Baeta Neves, Fabrício Monteiro Neves

e, por isso, se vinculam ao sentido específico do sistema correspondente, reduzindo, de forma intermediária, as possibilidades de orientação que estão disponíveis. Na teoria dos sistemas sociais, "encontraremos principalmente expectativas de comportamento" (Luhmann, 1998, p.107) que operam de forma generalizada. Como em outras teorias comportamentais, determinados comportamentos são esperados por todos, em determinadas situações. Nesse caso, o conceito de generalização desloca o enfoque tradicional da norma para a generalização das expectativas que conservam validade independentemente do acontecimento factual que é confrontado com sua própria validade (1998). Tal conceito permite ainda observar a sociedade e seu processo de reprodução de forma menos estática e rígida, como algumas perspectivas estruturalistas indicam. A inovação, portanto, ocorre em cada comunicação; o que se tem que discutir é a capacidade de tal evento inovador generalizar sentido, circular a despeito das condições distintas daquelas de sua produção.

Com esse referencial teórico, pode-se elaborar um modelo menos estático para se pensar a evolução da sociedade, partindo do processo de diferenciação ocorrido em sua estrutura primária, ou seja, a estrutura relativa aos sistemas parciais de funções (ciência, economia, religião, entre outros), bem como a relação entre eles. Deve-se ressaltar que os sistemas parciais (ou subsistemas) da sociedade são entornos uns para os outros, e a estrutura de relações entre eles define a estrutura da sociedade, ou seja, a forma como a sociedade organiza suas comunicações. Ademais, o aumento da complexidade é o elemento sensibilizador da diferenciação do sistema global da sociedade, portanto, sua fonte de inovações.

Para Luhmann (2007), a diferenciação funcional é a forma de diferenciação primária da sociedade moderna. Com base nessa forma de diferenciação a sociedade passa a ser caracterizada pela não-existência de um critério estrutural único que defina todo o sistema social; ao contrário, cada sistema de funções desenvolve mecanismos reprodutivos próprios que os define e diferencia dos demais. São diferentes pela função que cada um reproduz por meio de um código binário específico, que exclui outras formas de observação e estruturação existentes em seu ambiente externo. Desse modo, o sistema parcial convive com outras possibilidades de estruturação de expectativas, de outros sistemas parciais, outras formas de observar que permanecem como possibilidades de perturbação à sua lógica reprodutiva. Não há, nesse sentido, uma hierarquia quanto à função mais importante para a sociedade, posto que cada função se faz necessária para a reprodução do sistema global. Desse modo, assume-se que a sociedade é heterárquica, pois não há ponto de vista privilegiado ou comando que possa regular o todo. Cada comando, cada observação, as preferências e os motivos dizem respeito somente ao sistema e, fora de seus limites parciais, atuam somente como perturbação para outros sistemas funcionais.

O contexto sistemicamente estruturado de expectativas, dessa forma, torna-se conceito-chave nessa abordagem. É precisamente a forma da sociedade moderna o objeto privilegiado da teoria sistêmica exposta. Essa forma, como dito acima, é estruturada em torno de sistemas funcionais diferenciados que executam funções específicas e que se apresentam uns para os outros como entorno e, desse modo, fontes de irritação. É exatamente essa relação entre sistemas, descrita com o conceito de acoplamento estrutural, o que permite entender os processos internos a cada um deles. Várias abordagens sociológicas lidam com essa perspectiva, ainda que implicitamente, e várias teorias evolucionistas têm feito uso de conceitos sistêmicos para apresentar a evolução, coparticipativa, do âmbito social a que pretendem compreender. O que é comum, nessas abordagens, é a ideia de que as relações entre sistemas formam quadros normativos, por exemplo, para a ação econômica, como no caso da teoria dos regimes de produção (Teubner, 2005). Esses regimes são:

Totalmente assistêmicos, acoplamentos estruturais entre sistemas sociais autônomos que, no entanto, não se tornam sistemas autônomos com seus elementos, estruturas e limites próprios. 
Como acoplamentos estruturais, os regimes de produção são simples configurações formadas por componentes heterogêneos, por estranhas criações hermafroditas existentes na zona cinzenta entre a economia e a sociedade, em suma: híbridos econômicos (p.134).

Acoplamentos estruturais entre sistemas criam dinâmicas não-sistemáticas, ainda que possam significar contextos normativos para cada sistema envolvido, isto é, há uma coevolução, uma ação recíproca entre estruturas autônomas. Há vários exemplos da formação desses híbridos, no que tange à teoria evolucionista. Em relação à questão da mudança evolucionária intrínseca a essa teoria, o processo de produção e difusão de ciência, tecnologia e inovação (C,T\&I ${ }^{6}$ é compreendido como dinâmico, multifacetado e mobilizador de vários sistemas. Na sociedade atual, quatro sistemas se destacam na produção e difusão desses elementos, a saber: direito, política, ciência e economia. A partir da compreensão das relações entre os sistemas supracitados, abordar-se-á o regime de produção de C,T\&I. Para tanto, utilizar-se-á a compreensão de Teubner (2005) que, contestando uma lógica bipolar - envolvendo somente perturbação entre dois sistemas - em um regime de produção, propõe uma lógica cíclica de acoplamentos, portanto, multifacetada.

\begin{abstract}
Há miríades de relações intersistêmicas "selvagens", nas quais a economia e outros subsistemas sociais se irritam mutuamente. Condensam-se, para formar um regime de produção, apenas quando os canais de perturbação são traçados de tal forma que os impulsos para mudanças têm seus efeitos não só eventuais, pontuais e unilaterais, de um sistema para o outro, mas quando confluem para uma perturbação recíproca, no caso bilateral, e para um circuito de perturbações, no caso multilateral. Somente então nasce um regime de produção no sentido estrito (Teubner, 2005, p.139).
\end{abstract}

A formação desses regimes possibilita compreender as relações sistêmicas que orientam processos de inovação científicos e tecnológicos no interior de um sistema de C,T\&I contextualizado.

' Transformação nos sistemas mundiais de C, T \& I aqui é entendida como aquelas transformações mais específicas do processo mais geral de inovação da sociedade.
Esses regimes difusos de sistemas se acoplam e coevoluem, no interior dos quais cada sistema significa ambiente para outro, exercendo pressões ambientais que, de uma forma ou de outra, serão incorporadas e ressignificadas nos contextos internos significativos. ${ }^{7}$ Acrescente-se o fato de que existem contextos culturais difusos, também significativos para a ação sistêmica, contextos institucionais divergentes no plano dos Estados nacionais, por exemplo, o que exige, na análise, um cuidado especial com critérios seletivos institucionais próprios nas "províncias culturais" que se formam no interior da sociedade global.

Instituições econômicas participam sempre, concomitantemente, das histórias do direito, da política, da ciência e da pedagogia de seu espaço econômico, e demonstram, portanto, particularidades culturais que podem ser explicadas somente a partir da história dos outros sistemas (Teubner, 2005, p.142).

A ideia de "particularidades culturais" reforça o argumento de que uma diferenciação entre centro e periferia é possível no plano da sociedade global e no caso específico do sistema mundial de C,T\&I. A partir disso, pode-se falar em modernidade periférica em relação a uma modernidade central, se essa regra se impõe no tratamento de sistemas organizados, em oposição à dicotomia entre tradicional e moderno. $\mathrm{Na}$ modernidade periférica, a formação sistêmica se encontra deficitária quanto aos elementos seletivos que estruturam a autorreferencialidade dos sistemas complexos em sociedade centrais. Esse critério de duplicação, centro e periferia, portanto, supera o critério meramente econômico empregado nas teorias desenvolvimentistas da década de 1950 e 1960, embora, em tal âmbito significativo, o sistema econômico tenha de ser levado em conta na constituição dos regimes de produção.

Esse déficit de complexidade seletiva é o

\footnotetext{
Teubner (2005) apresenta três tipos de influências recíprocas entre instituições: as irritativas, em que os efeitos de uma perturbam os mecanismos de variação da outra; as simulativas, em que os critérios seletivos de uma são reconstruídos no interior da outra, e endógenosimbióticas, em que os resultados seletivos de uma se estabilizam por assimilação em outra.
} 
Clarissa Eckert Baeta Neves, Fabrício Monteiro Neves

que Neves (2006) chama de modernidade negativa. Os sistemas sociais periféricos convivem com problemas de hipercomplexidade ambiental, na medida em que as possibilidades de constituição de um “topos específico” (Neves, 2006, p.238) são limitadas. Sendo assim, a complexidade estruturada internamente não se "volta para si mesma" em um contexto de fortes pressões externas, não podendo se construir autonomamente em todos os âmbitos de constituição sistêmica: nas organizações, nas interações e nos sistemas sociais. Isso leva à inflação temática em torno de exigências econômicas e políticas, o que inflaciona também as expectativas inovadoras. Enfim, nesse contexto periférico de complexidade desestruturada e limites sistêmicos tênues, as interferências entre sistemas alteram critérios seletivos, códigos reprodutivos e a própria estrutura do sistema. É esse regime de acoplamentos difusos o que caracteriza a modernidade periférica e, em consequência, o âmbito de funcionamento do sistema de C,T\&I na periferia da sociedade global.

\section{ENSINO SUPERIOR, PESQUISA E INOVAÇÃO NA ALEMANHA}

A Alemanha enfrenta, nos últimos anos, enormes desafios no âmbito da formação de recursos humanos e na produção de conhecimento. Em paralelo à implantação da reforma preconizada por Bolonha, o governo projetou a pesquisa e a inovação no centro de sua política de crescimento. As prioridades foram definidas em torno da educação, pesquisa e inovação como soluções para os desafios nacionais e globais.

A determinação política do governo alemão, nesse sentido, reflete-se, cada vez mais, na implementação de programas responsáveis por criar as condições básicas necessárias a um ambiente favorável à inovação. Esses programas estipulam incentivos, valem-se de instrumentos diversos e buscam também inspirar o diálogo necessário e o exame crítico entre todos os atores envolvidos (BMBF, 2010).

Nas políticas de educação superior, de pes- quisa e inovação, chama atenção a ênfase em aumentar a eficiência dos "sistemas nacionais de inovação e educação”, tendo por referencia um conceito de inovação amplo. Assim, o conceito de inovação se afasta da noção de inovação como processo apenas linear e sequencial e que abrange apenas a pesquisa aplicada voltada para o mercado e que pode ser racionalmente planejada e realizada (BMBF, 2006, p.2). Em 2004, a Fraunhofer Gesellschaft, instituto de pesquisa não-universitário e um dos membros dos "Parceiros para a Inovação", autodefinindo-se como "o condutor no processo de inovação na Alemanha”, alertou para as graves deficiências estruturais nas políticas de inovação e, entre outras coisas, criticou a dominação do modelo linear (cf. Fraunhofer Gesellschaft 2004, p.75 e ss.). Sublinhou que era fundamental implementar uma nova capacidade de aprendizagem e flexibilidade na política, na sociedade, na economia e na ciência em relação a uma "política de inovação sistêmica":

O que é necessário para isso é que a comunicação e o intercâmbio sejam fortalecidos, pontos de interface sejam gerenciados, que seja reforçada a colaboração com o usuário fabricante, que sejam apoiadas a criação de novas redes (novas combinações) e que haja uma dissolução dos (destruição criativa) entrincheirados. Isso torna processos de aprendizagem possíveis, gera a atenção e o interesse para conceitos inovadores e torna mais fácil articular necessidades sociais e demandas do mercado (2004, p.77).

Como resposta às críticas com relação às políticas de inovação de governos anteriores, em 2005, o governo implantou o programa HightechStrategie, o maior programa de pesquisa em curso e novas políticas de inovação. Essa "estratégia global de inovação nacional” buscou, explicitamente, responder à questão do enfrentamento dos maiores desafios sociais atuais como saúde, proteção aos recursos naturais e ao ambiente, energia, mobilidade e segurança (Hightech-Strategie, 2006).

No entanto, segundo os relatórios do Ministério da Educação e Pesquisa (BMBF, 2010), o esforço de políticas de inovação, por si só, não seria suficiente para promover a capacidade de 
inovação na economia e na sociedade alemã.

A Alemanha, desse modo, investiu numa reforma do seu sistema de ensino superior, adotando as novas diretrizes do processo de Bolonha. Em paralelo, fomentou grandes projetos federais para reforçar a constituição de uma rede de Universidades de excelência, as ligações entre elas e a dinâmica da economia e do desenvolvimento social. Os principais projetos em andamento, além da Estratégia Hightech (2006), são a Iniciativa da Excelência, o Pacto da Educação Superior e o Pacto para a Pesquisa e Inovação (BMBF, 2010). Por fim, com o objetivo de fortalecer a eficiência do sistema científico alemão, outra estratégia empenhada foi a da internacionalização cada vez maior da ciência e da pesquisa. A seguir, serão destacadas as principais características de cada um dos programas em andamento.

\section{A reforma do ensino superior}

A Alemanha, em 1998 - juntamente com os Ministros responsáveis pela Educação Superior da Grã-Bretanha, Itália e França, reunidos nesse último país - pronunciou-se a favor da criação de uma Área Europeia de Ensino Superior (European Area for Higher Learning/Declaração da Sorbonne). No encontro seguinte em Bolonha, em 1999, participou da definição das principais orientações para as mudanças dos sistemas de ensino superior europeus, visando ao aumento da competitividade dos referidos sistemas, à promoção da mobilidade e da empregabilidade na Europa.

Essa reforma, conhecida como processo de Bolonha, pode ser considerada um exemplo de inovação no sentido amplo, consistindo numa proposta ousada de aperfeiçoamento dos sistemas de ensino superior dos países europeus e um instrumento de fortalecimento da União Europeia, visando, essencialmente, ao aumento da capacidade europeia de competição no cenário de globalização. Seis linhas de ação foram estabelecidas para criar um Espaço Europeu de Educação Superior, até 2010 (Bologna Declaration, 1999):
... a adoção de um sistema de graus facilmente compreensíveis e comparáveis; a adoção de um sistema baseado em dois ciclos de ensino, o Bachelor e o Master; o estabelecimento de um sistema de acumulação e transferência de créditos (tal como o ECTS - European Credit Transfer System, já em uso nos Programas Sócrates e Erasmus); a promoção da mobilidade de estudantes, docentes, investigadores e outros trabalhadores, removendo os obstáculos administrativos e legais ao reconhecimento de diplomas; a promoção da cooperação europeia na avaliação da qualidade da educação superior; a promoção do Espaço Europeu de Educação Superior.

A partir de então, uma série de conferências e comunicados, que se realizavam a cada dois anos, operacionalizaram e consolidaram as metas da reforma de Bolonha. Novas ênfases foram incluídas posteriormente na reforma: (a) a ênfase em estratégias de aprendizagem ao longo da vida, ou, educação continuada (Lifelong Learning); (b) a necessidade de se voltar para a dimensão social do processo, envolvendo mais ativamente grupos desprivilegiados e; (c) o incentivo à empregabilidade (London Communiqué, 2007). Houve uma adesão de número sempre crescente de países. Atualmente, há 47 países signatários da reforma. O Processo de Bolonha, portanto, foi uma decisão eminentemente política, que passou a ser vista como inevitável e irreversível pelos principais atores dos diferentes sistemas nacionais europeus.

Os argumentos que justificam a adesão da Alemanha para adoção do modelo de Bolonha basearam-se ora no reconhecimento das deficiências do ensino oferecido no antigo modelo, ora na atratividade do novo modelo proposto (Neves, 2011 p.192). A atratividade consistia na possibilidade de reconhecimento, no contexto europeu, dos créditos e diplomas; da ampliação das possibilidades internacionais de empregabilidade dos egressos; da importância da mobilidade de estudantes e professores; da possibilidade de aumentar a eficiência do investimento no ensino superior; da construção paulatina de um espaço europeu de educação superior no qual, livre de limitações nacionais, a ciência deveria ser desenvolvida numa forma de cooperação solidária (2011, p.193).

Através da articulação das duas esferas po- 
Clarissa Eckert Baeta Neves,

Fabrício Monteiro Neves

líticas, Ministério da Educação Federal alemão e a Conferencia dos Ministros da Educação dos Estados Alemães, envolvidas com a legislação e regulação da educação superior em conjunto e com a associação representativa das universidades, a Conferência dos Reitores Alemães, foi possível reunir a força e a pressão política para a reforma (Neves; Koppe, 2009a).

\section{A nova estrutura de ensino e a implantação do sistema de ciclos e créditos}

A formação no ensino superior através de ciclos é uma das principais características da reforma proposta no Processo de Bolonha. O Bachelor tem duração de três a quatro anos, com o objetivo de preparar os estudantes para o mercado de trabalho europeu, oferecendo um nível de qualificação apropriado. O Master, segundo ciclo, tem a duração de um ano e meio a dois anos de formação. Originalmente, ele foi concebido como o momento inicial da formação para a pesquisa, mas vem se desenvolvendo como complementar ao Bachelor na formação do profissional de nível superior (Erichsen, 2007, p.34; Ministry of Science, Technology and Innovation, 2005).

O doutorado foi incluído como um terceiro ciclo no Comunicado de Berlim, em 2003, e pode durar de 3 a 4 anos letivos (Berlin Communiqué, 2003). Atualmente, o doutorado é considerado como o primeiro ciclo de formação de pesquisadores nas diversas áreas do conhecimento. Ele permanece como ciclo a ser oferecido exclusivamente pelas universidades.

Em 2004, havia, na Alemanha, 11.183 cursos no total, dos quais 19\% eram Bachelor e Master. No semestre de inverno 2010/2011 o total de cursos oferecidos foi de 14.094 , dos quais $81 \%$ correspondem a Bachelor (6.047) e Master (5.502). Nas universidades $78,1 \%$ dos cursos já seguem a estrutura de ciclos. Nas Escolas Superiores Especializadas (Fachhochschule) 96,8\% dos cursos já seguem o novo formato de Bachelor e Master. Nas Escolas Superiores de Música e Artes, o percentual gira em torno de
50\% (Hochschulrektorenkonferenz, 2010).

Desde 2009, esse novo sistema vem sendo debatido, de forma intensa. Há um reconhecimento de que a reforma foi importante e de que ela foi uma "história de sucesso". Para muitos professores na Alemanha, no entanto, ela é vista atualmente como um "quadro emaranhado" que precisa sofrer ajuste. Alguns falam até da reforma da reforma, outros mencionam que a reforma precisa é ser adequadamente implantada.

Os estudantes, por sua vez, em 2009 fizeram protestos e greves em diversas universidades alemãs, chamando a atenção para a excessiva burocratização da reforma, a falta de flexibilidade dos currículos, uma excessiva maratona de provas e a consequente pressão sobre o desempenho (Neves, 2011). Segundo as diversas manifestações dos organismos e das próprias IES, os desafios são muitos, e fala-se na necessidade de implantar a segunda fase do processo de Bolonha, com o fortalecimento dos recursos financeiros para o ensino superior.

\section{Os programas de fomento à pesquisa e inovação}

O sistema de pesquisa e inovação na Alemanha apresenta uma estrutura bastante diferenciada entre instituições públicas, algumas privadas Universidades e as Escolas Superiores Especializadas (Universidades de Ciências Aplicadas, conforme nomenclatura do DAAD) e instituições de pesquisa não-universitárias, na sua maioria privadas, sem fins lucrativos. Entre as principais estão: Sociedade Fraunhofer, Comunidade Helmholtz de Centros Alemães de Pesquisa, Sociedade Leibniz (WGL), Sociedade Max Planck (MPG).

O sistema federativo da Alemanha leva tanto a União como os Estados a investirem crescentemente em pesquisa e inovação. Em 2005, foram investidos 9 bilhões de euros, que passaram a 10,9 bilhões de euros em 2008, e a expectativa para 2010 era de 12,7 bilhões de euros. No entanto, o setor que mais investe em pesquisa e inovação é o setor da economia, que, em 2008, 
alcançou a cifra de 46,1 bilhões de euros. A despesa interna bruta em P\&D nas instituições do ensino superior totaliza aproximadamente 11,1 bilhões de euros por ano (2008) e é financiada com recursos públicos (82\%), da indústria (14\%) e internacionais (4\%) (BMBF, 2010, p.18).

Os dados revelam certa constância de investimentos com relação ao PIB. Em 2007, foram investidos em torno de 2,53\% do PIB para pesquisa e inovação. Em 2008, a previsão era de 2,64\%. Entre 2005 e 2007, em dados absolutos, ocorreu um crescimento de recursos de 55,7 bilhões de euros por ano para 61,5 bilhões por ano, (10\%); $\mathrm{e}$ a previsão para 2008 de gasto com C,T\&I era de 65 bilhões de euros (BMBF, 2010, p.19).

Em 2007, a despesa interna bruta em T\&I atingiu 61,5 bilhões de euros, sendo mais de dois terços dos recursos provenientes da indústria (68\%), quase $28 \%$ da União e dos Estados (Länder) e os 14\% restantes de investimentos externos. A proporção entre o financiamento público e o privado varia de acordo com o tipo de instituição e de pesquisa (básica ou aplicada). A entidade central de fomento à ciência e à pesquisa em universidades e institutos financiados pelo poder público éa Sociedade Alemã de Pesquisa (DFG) (BMBF, 2010).

\section{A Estratégia Hightech}

A estratégia Hightech é uma política que busca relacionar o campo da política com as atividades de pesquisa e inovação em amplas áreas temáticas. O objetivo foi o de criar, na Alemanha, mercados de referência, fortalecendo o trabalho conjunto entre ciência e economia. Vários aspectos foram enfatizados, como a melhoria das condições para inovação, o financiamento da inovação, a otimização das normas e standards, bem como das condições de referencias para proteção da propriedade intelectual e ainda fomento das novas gerações (Hightech-Strategie, 2006).

O fomento à pesquisa e inovação está focado em cinco campos prioritários para os próximos 10 a 15 anos, a saber: clima e energia; saúde e alimen- tação; mobilidade; segurança; comunicação. Os resultados de pesquisa deverão rapidamente ser transformados em inovação tanto para o mercado como para a sociedade. Para isso, a União estabeleceu reforçar as relações de troca entre as IES, os centros de pesquisa não-universitários e as empresas, no que se refere à transferência de conhecimento, seja como tecnologias ou inovação. As áreas de fomento chamadas de tecnologias-chave são: bio e nanotecnologia; micro e nano eletrônica; tecnologias óticas; sistemas micro; tecnologia espacial; tecnologias de comunicação e informação. Elas, segundo o programa, são fundamentais para solucionar os grandes desafios globais. Outro aspecto importante dessa política é a ênfase no diálogo entre a sociedade, a pesquisa e inovação, especialmente nos casos de tecnologias controversas. Para isso, propõem explorar especialmente o trabalho interdisciplinar entre as ciências da natureza, humanas, jurídicas e sociais (BMBF, 2010).

\section{Pacto das instituições de ensino superior 2020}

Para manter o desempenho das Universidades e ampliar o acesso a um número crescente de novos estudantes, o governo federal e os estaduais decidiram, em 2007, implantar o Pacto da Educação Superior 2020, prevendo a criação de cerca de 100.000 novas vagas. O desenvolvimento atual do programa reflete os resultados positivos. Em 2005, cerca de 360 mil novos estudantes iniciaram seus estudos, correspondendo a $36 \%$ da faixa etária de 18 a 20 anos; no ano de 2010, foram 441800 novos alunos (46\% da faixa etária).

Na primeira fase desse programa, já foram incorporadas 182.193 matriculas novas, ultrapassando a previsão inicial, das quais 54.769 em universidades e as demais nas Fachhochschulen. Esse programa foi ampliado até 2015, devendo criar mais 275.000 novas vagas. Nessa segunda fase, o governo federal irá investir 4,7 bilhões de euros (BMBF/ Hochschulpackt, 2010).

Para cada nova vaga, eram despendidos 
Clarissa Eckert Baeta Neves, Fabrício Monteiro Neves

22.000 euros, passando, nesta nova fase, a 26.000 euros, dos quais a União assume 13.000 euros e o restante os respectivos estados. Atualmente, a Alemanha conta com 2.121.178 alunos matriculados, dos quais 51,8\% em universidades e 38,9\% em Escolas Superiores Especializadas; existem 370 IES, das quais 110 são universidades, 189 são Escolas Superiores Especializadas, 51 Faculdade de Artes, 30 Faculdades de Administração pública, 14 Faculdades de Teologia e 6 Faculdades de Educação (BMBF, 2010a, p.49).

\section{A iniciativa de excelência}

Em 2005, foi criado o programa Iniciativas de Excelência, num acordo entre a União e os Estados, com o objetivo de fomentar a ciência e a pesquisa nas universidades alemãs. A União (75\%) e os Estados (15\%) investiram 1,9 bilhões de euros nesse programa para o período de 2006 a 2010 (BMBF, 2010b).

O programa tem três linhas de fomento principais:

a) Um programa de doutoramento, a Graduate School (Graduiertenschulen), que deve ser estruturado em módulos numa ampla área científica e campo de pesquisa de ponta. Na primeira fase, foram apoiados 39 programas de doutoramento por cinco anos com um orçamento de, em media, 5,7 milhões de euros cada.

b) Os Clusters de Excelência, que deverão consolidar centros de pesquisa com visibilidade internacional e capacidade de concorrência. Também devem realizar parcerias com instituições nãouniversitárias de pesquisa, com as Escolas Superiores Especializadas, e com o amplo setor da economia, preparando o campo para as novas gerações. Cada um dos 37 Clusters recebeu um investimento de 31,8 milhões de euros pelo prazo de cinco anos.

c) A ultima linha de projetos é formada pelos programas chamados de Concepção do Futuro, que tem por objetivo intensificar a pesquisa de ponta. Para a implantação desse programa, foram selecionadas 9 universidades que deveriam ter, pelo menos, um programa de doutoramento no novo formato, um Cluster de Excelência, assim como um amplo programa de desenvolvimento da pesquisa. Para cada universidade, foram previstos 210 milhões de euros por ano (BMBF, 2010b).

Os projetos referentes às duas primeiras linhas são analisados e avaliados pela Sociedade Alemã de Pesquisa/DFG. Os projetos da ultima linha são avaliados por uma comissão estratégica definida pelo Conselho Científico e pela DFG. O Conselho Científico é formado por cientistas bem como representantes da esfera pública federal e estadual. Ele é um instrumento de cooperação federativa para o fomento da ciência na Alemanha e tem uma dupla função de mediação entre a ciência e a política e a estrutura federalista entre União e os Estados. É formado por 32 membros nomeados pelo presidente da República, 24 deles sugeridos pelo DFG, e pelos institutos não-universitários e 8 representantes da esfera pública por sugestão do governos federal e dos governos estaduais (DFG, 2010).

Em junho de 2009, foi definida, pela União e pelos Estados, a continuação do programa de novembro de 2012 até final de 2017, com um acréscimo de recursos de 30\%, num total de 2,7 bilhões de euros. Em 2010, ocorreu uma nova rodada de seleção de projetos. Foram encaminhadas 227 propostas de 65 universidades. Ao todo foram selecionados 59 projetos envolvendo 34 universidades: 25 projetos de programas de doutoramento, 27 Clusters de excelência e 7 projetos de Concepção do Futuro. As universidades selecionadas têm prazo até setembro de 2011 para encaminhar o projeto final. Cabe mencionar que os programas em andamento podem solicitar prorrogação (BMBF, 2010b).

\section{O pacto para pesquisa e inovação}

Esse pacto foi definido em 2005 para o período de 2006 a 2010. Em 2008, ele foi ampliado para 2015. O pacto faz parte da ofensiva do governo alemão para o crescimento e a inovação, inves- 
tindo adicionalmente mais 6 bilhões de euros para a pesquisa. Enquanto a Iniciativa de Excelência é destinada ao fomento da pesquisa nas universidades, esse Pacto fomenta e prevê a garantia de recursos para os importantes Institutos de pesquisa não-universitários e para a Fundação Alemã de Pesquisa/DFG, como agência de fomento, com o objetivo de: desenvolver de modo dinâmico o sistema científico; fortalecer a integração no sistema científico; desenvolver novas estratégias do trabalho de cooperação internacional; estabelecer novas parcerias entre a ciência e a economia; garantir a presença dos melhores pesquisadores, de modo permanente, na ciência alemã (BMBF, 2010b).

Em 2009, a União e os Estados, reconhecendo o impacto positivo das políticas de pesquisa e inovação, decidiram pela sua continuidade, ampliando em 18 bilhões de euros os recursos para o sistema da ciência, para o período de 2011 a 2015. Também foram reforçados os objetivos da política de pesquisa, especialmente a intensificação do desenvolvimento e da interconexão do sistema da ciência, a ampliação de novas estratégias para a cooperação internacional e a intensificação das parcerias entre a ciência e a economia (BMBF, 2010b).

$\mathrm{O}$ que se pode concluir é que a Alemanha definiu claramente políticas para fortalecer o sistema da ciência, através de investimentos importantes em pesquisa e inovação, envolvendo todos os atores, como universidades, institutos de pesquisa, agências de fomento. Constata-se uma forte adesão por parte dos diferentes atores às políticas, especialmente ao programa da Hightech-Strategie, das universidades, que aderiram às Iniciativas de Excelência e ao Pacto do Ensino Superior, bem como dos institutos de pesquisa, que aderiram ao Pacto para Pesquisa e Inovação. Além do mais, a Alemanha pode contar com um forte investimento em pesquisa e inovação por parte do sistema econômico.

Na sua mais recente avaliação, o GII (2011) reconhece que a Alemanha vem apresentando um excelente desempenho nos índices de output produção científica e de inovação -, mas ainda apresenta uma fraqueza relativa no lado dos índi- ces de input - instituições, capital humano e de pesquisa, infraestrutura, sofisticação de mercado, sofisticação de negócios. Há, nesse sentido, uma convergência de percepções, pois as políticas anteriormente descritas pretendem encaminhar soluções precisamente para as "deficiências" da Alemanha nestes aspectos. Neste ano de 2011, ela aparece, pela primeira vez em 12 lugar no ranking geral, mas tem estado sempre entre as dez primeiras. Dado que as políticas de apoio à pesquisa $\mathrm{e}$ inovação são bem recentes, os resultados esperados acontecem num mais longo prazo.

\section{ENSINO SUPERIOR, PESQUISA E INOVAÇÃO NOBRASIL}

Nas últimas décadas, o Brasil tem experimentado um cenário de mudanças no que tange à incorporação da referência "inovação" nos processos educacionais, científicos, políticos e econômicos. Tal processo, no entanto, enfrenta diversas dificuldades, entre elas, aquelas ligadas ao histórico descompasso entre organizações universitárias e empresas, políticas pouco efetivas na promoção de desenvolvimento tecnológico, limitações nos financiamentos de C,T\&I, e, não menos importante, a ausência de uma "cultura da inovação" no sistema de personalidade (Oliveira et al., 2009). A consequência dessas dificuldades pode ser verificada na posição do Brasil no GII (2011), 47º posição em termos globais.

Nos últimos anos, várias iniciativas com foco na inovação, em sentido amplo, foram implementadas. Tais iniciativas buscam aumentar o ingresso nas universidades, criam fundos setoriais para áreas estratégicas, fomentam a criação de grupos de excelência científica e tecnológica e o aumento dos investimentos em P\&D. Porém a maior parte das iniciativas são focadas na criação de um novo marco legal e na inclusão de estudantes no ensino superior para o aumento de pessoal envolvido em de P,D\&I. Destacam-se o programa de expansão para IES federais (REUNI), a Lei de Inovação (2004), a Lei do Bem (2005), os Fundos 
Clarissa Eckert Baeta Neves, Fabrício Monteiro Neves

Setoriais, e o Programa de Aceleração do Crescimento da Ciência e Tecnologia (lançado em 2007). ${ }^{8}$

A seguir, vamos retomar os programas de inovação citados acima, já apresentados em outros trabalhos (Viotti, 2008; Schwarztman, 2008). Atentaremos para o fato de haver ainda uma incipiente articulação entre os sistemas envolvidos em processos inovativos, criando assimetrias entre âmbitos, muitos deles com uma dinâmica interna de resistência à inovação.

\section{O programa REUNI}

No Plano Nacional da Educação de 2000, a projeção para 2010 era de incorporação de 30\% dos jovens de 18 a 24 anos ao nível superior. No início desta década, o percentual dessa população correspondia a 10\%. Apesar da expansão da matrícula, chegou-se apenas a $14.5 \%$ de taxa líquida (que compara o número de estudantes de 18 a 24 anos com o total de jovens nessa coorte) e $23,8 \%$ com relação à taxa bruta (que considera o total de estudantes independentemente da idade em relação à coorte), uma das mais baixas do continente latino-americano (PNAD/IBGE, 2009). Logo, uma das preocupações do governo na Administração Lula, foi investir na reestruturação das IES federais, com o programa REUNI/Plano de Reestruturação e Expansão das Universidades Federais.

O Brasil conta atualmente com 6.379.299 de estudantes no ensino superior (presencial e à distancia). A expansão tem se dado pelo maior crescimento da oferta de vagas e de matrículas no segmento privado (75\% do total das matrículas), mantido, basicamente, pela receita proveniente das mensalidades pagas pelos alunos e (ou) suas famílias. O segmento público, totalmente gratuito para os estudantes matriculados, sem consideração de renda ou da capacidade econômica, concentra 25\% das matrículas (MEC/INEP, 2009).

O Brasil possui um sistema de pós-graduação bem consolidado. No mestrado, há 108.820

${ }^{8}$ A legislação está disponível em: www.portalinovacao. mct.gov.br/pi/\#/pi alunos matriculados e, no doutorado, 64.588, a maioria nas IES públicas. O país forma por ano cerca de 40.000 mestres e 11.000 doutores (CAPES/MEC, 2011). O número de pesquisadores, no Brasil, a cada mil indivíduos, foi estimado em 0,98\% em 2004, número relativamente baixo, considerando ainda que grande parte desse contingente realiza pesquisa no setor público. Fundamental na sustentação desse sistema nacional de pósgraduação senso estrito é a avaliação trienal de todo os cursos de mestrado e doutorado. Essa avaliação, nos últimos anos, tem procurado incorporar indicadores de excelência vinculados ao esforço de desenvolvimento tecnológico e, em particular, à inovação, como o registro de marcas e patentes. O impacto de medidas nessa direção é ainda pequeno. A excelência da pós-graduação brasileira é ainda fortemente marcada pelos indicadores propriamente acadêmicos.

A principal política governamental para o ensino superior federal, instituída em 2007, foi o Programa de Apoio aos Planos de Reestruturação e Expansão para as Universidades Federais (Reuni). Seu objetivo era a expansão do acesso e a ampliação das matrículas nas instituições públicas, a partir de um melhor aproveitamento da estrutura física e de recursos humanos existentes nas universidades federais. O Programa também tinha como meta a elevação gradual da taxa de conclusão média dos cursos de graduação presenciais para 90\% e da relação de 18 alunos de graduação em cursos presenciais por professor, ao final de cinco anos. As despesas são financiadas com as dotações orçamentárias anualmente consignadas ao Ministério da Educação. Até 2012, está previsto um investimento de $\mathrm{R} \$ 2,4$ bilhões de reais (ANDIFES, 2010).

A expansão recente das universidades federais brasileiras e de reestruturação da infraestrutura contou com a adesão da totalidade das 54 instituições federais de ensino superior. Implicou a criação de dez novas universidades federais em todas as regiões e a criação e consolidação de 49 campi universitários. Com relação à oferta de vagas, entre o ano de 2006 e 2010, foram cria- 
das 77.279 novas vagas e 1.035 novos cursos de graduação presencial (ANDIFES, 2010, p.11). Outros aspectos a destacar são a preocupação com a redução das taxas de evasão, ocupação de vagas ociosas e a reestruturação acadêmico-curricular, empreendidas por 85\% das IES que aderiram ao REUNI. A preocupação com a qualidade da oferta, para além da ampliação do número de vagas na educação superior pública, leva o REUNI a atuar em outras cinco dimensões: reestruturação acadêmico-curricular; inovação pedagógica; mobilidade intra e interinstitucional; compromisso social das universidades e articulação entre graduação, pósgraduação e os demais níveis educacionais (ANDIFES, 2010).

Como se pode observar, esse é um Programa que atinge apenas as universidades federais e trata prioritariamente de expansão da matrícula e criação de novos cursos de graduação. No tocante ao tema da inovação, o REUNI delega a cada universidade estipular medidas concretas nesse campo. Seu impacto é, portanto, difuso e aleatório.

\section{O marco legal da pesquisa e inovação}

A temática da inovação foi introduzida oficialmente nos documentos sobre C\&T a partir da II Conferência Nacional de Ciência Tecnologia e Inovação, em 2001. Em 2005, a III Conferência Nacional de Ciência, Tecnologia e Inovação deu ênfase ao potencial da inovação para o desenvolvimento da indústria nacional, para o desenvolvimento das economias regionais e a superação de situações de desigualdades. Também as bases da nova Política Industrial, Tecnológica e de Comércio Exterior (PICTE), lançadas com a divulgação do documento de diretrizes ocorrido no final de 2003, já apontavam para as importantes iniciativas voltadas para a inovação. As diretrizes definiram, como objetivo da PICTE, aumento da eficiência da estrutura produtiva, aumento da capacidade de inovação das empresas brasileiras e expansão das exportações. As iniciativas abaixo se inserem nesse contexto de construção de uma dinâmica econômica e social voltada para a inovação.

A Lei de Inovação, aprovada em 2004 e regulamentada em 2005 (Lei No 10.973 de 21 de novembro de 2004), tem como objetivo principal estimular universidades e institutos de pesquisa públicos a contribuírem para o processo de inovação. Seu propósito original era o de criar mecanismos que facilitassem a circulação de pesquisadores entre as instituições de pesquisa e as empresas e a promoção da cooperação entre universidade e empresa na área de pesquisa e desenvolvimento tecnológico. Através da articulação de canais apropriados, deveria ocorrer o aumento da interação entre essas instituições e o mercado: o compartilhamento de laboratórios entre o setor produtivo e as universidades e centros de pesquisa; a permissão para que universidades (públicas) participassem, minoritariamente, do capital de empresas tecnológicas; o apoio a mecanismos de remuneração diferenciados a pesquisadores envolvidos em projetos de inovação e sua participação nos ganhos derivados da exploração de criação protegida por direitos de propriedade intelectual; e a possibilidade de que o pesquisador obtivesse uma licença em sua instituição de pesquisa para formar empresa que explorasse inovações tecnológicas desenvolvidas a partir de suas pesquisas (Balbashewsky, 2010).

Com esses propósitos, a lei regula a transferência para empresas privadas de tecnologias geradas por instituições de pesquisa e permite o compartilhamento com as empresas de sua infraestrutura, seus equipamentos e recursos humanos. Além disso, a Lei de Inovação autoriza a participação minoritária do governo federal no capital de empresas privadas que visem ao desenvolvimento de inovações (Viotti, 2008). Nota-se, nesses elementos, a busca pelo adensamento das relações intersistêmicas, principalmente entre economia, ciência e política.

Algumas imperfeições e falhas no teor da lei são apontadas por críticos, tais como amplitude e excesso de detalhes, falhas das normas que tratam da interação entre inventor, universidade e capital de risco, falta de definições claras voltadas ao estímulo das micro e pequenas empresas e o 
Clarissa Eckert Baeta Neves, Fabrício Monteiro Neves

problema das questões jurídicas entre as parcerias público-privadas, e a necessidade de flexibilidade e autonomia das instituições públicas na sua relação com o setor privado (Botelho; Bueno, 2008). Outros também apontam para os "perigos" de que essa lei possa representar mais um estágio no processo de aprofundamento da privatização do setor público (Viotti, 2008), criando assimetrias na participação entre as esferas pública e privada nos resultados dos empreendimentos, cabendo, ao fim, a socialização dos ônus e a privatização dos bônus.

PelaLei 10.973, foi instaurada a obrigatoriedade de instalação de Núcleos de Inovação Tecnológica (NITs) em todos os Institutos de Ciência e Tecnologia (ICTs). Os NITs são responsáveis pela gestão de política de inovação, pela avaliação de atividades de pesquisa, assim como pelo acompanhamento do processo de transformação da criação em inovação tecnológica, promovendo e gerenciando parcerias entre universidade e empresas.

Outra medida importante foi a "Lei do Bem" (Lei ${ }^{\circ} 1.196$, de 21 de novembro de 2005), que consolidou e ampliou incentivos fiscais preexistentes, assim como estabeleceu novos e substanciais incentivos a empresas que realizam atividades de C\&T e inovação tecnológica. Além desses incentivos fiscais, a lei autoriza o governo federal a conceder subvenções econômicas a empresas que contratarem pesquisadores detentores de título de mestrado ou doutorado, para a realização de atividades de C\&T e inovação tecnológica. Essa lei visava a superar uma carência histórica vinculada à baixa capacidade de absorção de mestres e doutores em empreendimentos industriais.

\section{O fomento à pesquisa e à inovação}

O principal fundo para o financiamento de pesquisa nas instituições universitárias e de educação superior é o Fundo Nacional de Desenvolvimento Científico e Tecnológico (FNDCT). Seu orçamento para 2008 foi de $\mathrm{R} \$ 2,63$ bilhões, incluindo o orçamento da agência de inovação FINEP (Financiadora de Estudos e Projetos) e da agência de pesquisa CNPq (Conselho Nacional de Desenvolvimento Científico e Tecnológico), além de outras instituições e unidades ministeriais. Embora o FINEP gerencie os recursos do FNDCT e receba um fundo adicional para seus próprios programas de inovação, a principal fonte de recursos para a pesquisa é ainda o CNPq. O financiamento institucional também é feito pelo Ministério da Ciência e Tecnologia (MCT), através de seus próprios institutos de pesquisa. O Brasil investiu, em 2009, 1,57\% do PIB em C\&T\&I, sendo que 53,89\% dos recursos foram públicos e 46,11\% de origem empresarial, estatal e privada (BRASIL/MCT/ CNPq, 2010).

Os Fundos Setoriais de Apoio ao Desenvolvimento Científico e Tecnológico, outra importante fonte de recursos, tem como objetivo assegurar a ampliação e a estabilidade dos recursos destinados ao desenvolvimento de ciência, tecnologia e inovação no Brasil. As receitas dos Fundos são oriundas de parcelas dos royalties gerados pela produção de petróleo e gás natural e de outras contribuições incidentes sobre o faturamento de empresas de setores específicos, ou sobre certos tipos de transação, como é o caso, por exemplo, das referentes aos pagamentos por uso ou aquisição de conhecimentos tecnológicos provenientes do exterior. Hoje, existem 16 Fundos Setoriais, sendo 14 referentes a setores específicos e dois de natureza transversal (BRASIL/MCT/CNPq, 2008).

\section{Programas de apoio à pesquisa e inovação nas Universidades}

As universidades públicas sãoresponsáveis pela parcela mais significativa da pesquisa desenvolvida no Brasil. O fomento à pesquisa dá-se, de um modo geral, por formas tradicionais de apoio: bolsas de pesquisa e fomento a grupos através de editais que direcionam a atividade de pesquisa para questões consideradas estratégicas. Atualmente, as principais agências de fomento, como FINEP, CNPq e CAPES (além das Faps), operam através de editais anuais, seja para apoiar o pesquisador ou grupos 
de pesquisa, seja ainda para a formação de redes de pesquisa nacionais ou internacionais. ${ }^{9}$ Os editais introduzem elementos de competição entre os demandantes pelos recursos, o que é comum. O problema que se observa é a grande competição por recursos escassos e, muitas vezes, descontínuos.

Uma iniciativa a destacar é a criação dos Institutos Nacionais de Ciência e Tecnologia (ICTs), cujo número, em todo o país, já chega a 123 projetos aprovados, envolvendo universidade, empresa e institutos de pesquisa. Tais projetos direcionam esforços para áreas como saúde, biotecnologia, nanotecnologia e energia, cuja meta é "mobilizar e agregar, de forma articulada com a atuação em redes, os melhores grupos de pesquisa em áreas de fronteira da ciência" como definido no PACTI (BRASIL/MCT/CNPq, 2011). Seu financiamento se dá por consórcios compostos por várias fontes federais (CNPq, Capes, FINEP, BNDES) e também por FAPs (Fundações de Amparo à Pesquisa - estaduais) e pela Petrobrás.

De forma ampla, tais iniciativas, voltadas para a promoção de C,T\&I, tiveram como consequência tornar mais denso o acoplamento estrutural entre os sistemas científico, econômico e educativo, buscando promover um efetivo sistema nacional de inovação. No entanto, todas essas iniciativas dependem, fundamentalmente, da qualidade, do número de estudantes e da relação que a universidade estabelecerá com outros sistemas que formam a dinâmica da inovação na sociedade contemporânea, como a economia e a educação básica. Se a alfabetização foi um desafio até recentemente, para a inovação e a manutenção dos atuais padrões de crescimento econômico, será fundamental a resposta que as últimas iniciativas da política universitária darão no sentido da incorporação de pessoal, diversificação das capacidades e diálogo com as mais diversas instâncias da sociedade.

${ }^{9}$ Principais editais CNPq/MCT: RHAE (1988) RHAE-Inovação (2003); Pronex (Programa de Apoio aos Núcleos de Excelência,1996); Institutos Milenium substituíram o PRONEX em 2000; Institutos Nacionais de Ciência e Tecnologia - INCTs substituem os Institutos Milenium em 2007.

\section{Interações entre universidades e empresas}

Uma das maiores dificuldades que se observa ainda hoje é a aproximação das universidades, especialmente as públicas, com as empresas. Moreira et al. (2007, p.7), em um estudo sobre inovação, apontam os fatores que prejudicam uma possível interação. Por parte das universidades, destacam: ausência de empreendedores tecnológicos; estágio embrionário das agências de transferência de tecnologia; ineficiência na utilização dos recursos de fomento à pesquisa; má gestão de projetos de pesquisa desenvolvidos em parceria com as empresas; incentivo às publicações, inviabilizando a proteção do conhecimento; desconhecimento da propriedade intelectual. Pelo lado do mercado, eles apontam: pouca disseminação da cultura da inovação; pouca presença de pesquisadores nas empresas, dificultando a interlocução com a academia; incentivos de curto prazo, inviabilizando investimentos em pesquisa aplicada; legislação desfavorável ao licenciamento exclusivo de uma tecnologia; baixo nível de investimentos em P\&D por parte das empresas nacionais. Poderíamos acrescentar, ainda, dificuldades em assumir riscos inerentes ao processo de inovação. Para esses autores,

O processo de geração de conhecimento e a transformação desse conhecimento em riquezas, embora com alguns avanços nos últimos anos, ainda é muito incipiente. Há vários indicativos de que a ciência e o mercado brasileiro não se comunicam de forma eficiente e também vários são os fatores que oferecem resistência à exploração com sucesso das oportunidades de inovação geradas nas universidades e centros de pesquisa brasileiros. E estes fatores não são de responsabilidade unicamente da academia ou das empresas, mas de ambos e do governo (Moreira et al., 2007, p. 5).

Paralelamente às linhas da política mais tradicional de C\&T e apoio à P\&D, como a formação de mestres e doutores e o apoio a grupos ou redes de pesquisa, um conjunto de novas medidas e programas vem incentivando as instituições universitárias e de pesquisa a apostar cada vez mais em processos inovativos. Esses novos rumos da política de C,T\&I apontam na direção de uma mai- 
Clarissa Eckert Baeta Neves, Fabrício Monteiro Neves

or aproximação das universidades com empresas e o setor produtivo, buscando reforçar a importância da inovação em cada âmbito e entre eles.

No entanto, muitas dificuldades emergem, desde incapacidade de os atores universitários lidarem com as empresas, alegando riscos de privatização das instituições públicas, até falta de iniciativa dos empresários, na medida em que o investimento em C\&T é visto por eles como responsabilidade do governo, e se isentam de assumir compromissos privados com C\&T\&I. As estatísticas revelam que apenas $1 \%$ dos doutores atuam na indústria, 4\% na área da saúde, e 47\% na administração pública e 48\% na área da educação (Viotti, 2008).

Schwartzman (2008) chama atenção que

... o Brasil ainda está longe de criar um sistema de inovação que consiga efetivamente conectar os diferentes setores que deveriam integrar este sistema - governo, setor produtivo e empresarial, comunidade científica, universidades. A dificuldade principal é que não se trata, simplesmente, de uma questão de engenharia institucional, mas de culturas e interesses setoriais que divergem, e o governo não tem clareza ou determinação para fazer convergir.

Nesse sentido, esse conjunto de medidas revela a relativa dificuldade do Brasil em criar um efetivo sistema nacional de inovação. Segundo o GII (2011), o Brasil alcançou a $32^{\mathrm{a}}$ posição em indicadores de output, mas apenas o $68^{\circ}$ lugar em indicadores de input, o que lhe confere a classificação geral de $47^{\circ}$ lugar. O GII destaca, entre o output, a crescente produtividade brasileira, mas aponta que sua fraqueza é revelada por uma série de indicadores de input, especialmente, o ainda baixo gasto com C\&T (1,57\% do PIB).

O que se evidencia é que, na ausência de articulação entre os sistemas responsáveis pela dinâmica de inovação, nada adianta o fomento a P,D\&I, a formação de milhares de mestres e doutores e um marco legal propício, já que inovação é resultado do que acontece no limite entre os sistemas (Neves, 2009).

No entanto, cada vez mais, as práticas organizacionais direcionam-se no sentido de potencializar a relação universidade (como organização científica), agência financiadora governamental (como organização política) e empresa (organização econômica). As iniciativas acima conduzem a uma lógica cíclica voltada para a inovação, mesmo que, ainda, somente como objetivo, diretriz norteadora ou, na linguagem sistêmica, expectativa.

\section{CONSIDERAÇÕES FINAIS}

Inovação é o grande desafio da sociedade contemporânea. Desenvolvimento, seja qual for a definição empregada, depende da transformação sempre mais intensa e contínua do conhecimento em valor social e econômico. Nesse contexto, a formação de recursos humanos, a produção de tecnologia e inovação e a própria reorganização de instituições como as universidades e os institutos de pesquisa são pressionados para que sirvam a esse propósito.

Inovação transformou-se, portanto, num item central das agendas nacionais de desenvolvimento. As razões para isso vinculam-se, basicamente: - À nova realidade da competição econômica em escala global e ao espetacular avanço das novas tecnologias de informação e comunicação.

- Ao avanço da Sociedade do Conhecimento e seu requerimento contínuo de recursos humanos sempre mais qualificados e constante demonstração de domínio sobre a produção científica e tecnológica.

- Aos desafios da sustentabilidade do desenvolvimento.

- À profunda transformação sociodemográfica das populações e suas pressões sobre o mercado de trabalho produtivo.

- Às condições de segurança e de convívio social em megacidades.

- Às exigências de maior e mais efetiva participação política em democracias com representação de interesses muito desagregada.

- Ao necessário aumento de eficiência e eficácia das políticas públicas em todos os setores.

É importante registrar que o desafio da 
inovação é percebido como uma questão nacional, ou seja, cada nação precisa enfrentá-lo e buscar ser bem sucedida através do aproveitamento de seus recursos e da exploração de suas próprias potencialidades. Assim, tanto as nações definidas como de modernidade central, como as de modernidade periférica veem-se diante do mesmo desafio. A resposta de cada uma varia, no entanto, em virtude, precisamente, dos recursos de que dispõe e da sua capacidade de mobilizá-los adequadamente para obter os resultados desejados.

Ao buscar reconstruir as experiências recentes da Alemanha e do Brasil, é preciso, antes de tudo, ter presente que os recursos de cada um, nesta batalha, são bastante distintos. Isso não significa que os resultados dos esforços de cada um estejam previamente determinados. A última crise econômica mundial mostrou que os países emergentes apresentaram condições de recuperação melhores e mais rápidas com relação aos piores efeitos da crise. Suas perspectivas na nova ordem sugerem, além disso, que essas nações poderiam queimar etapas e acelerar o processo de construção de economias líderes.

A disposição sobre recursos distintos implica, assim, apenas que a amplitude, a ousadia, a organicidade e a consistência das medidas e das iniciativas do setor público e do setor privado podem demandar graus de complexidade específicos tanto na formulação de políticas de P\&I como na sua implantação.

A Alemanha destaca-se por dispor de um sistema de formação de recursos humanos e de produção de conhecimento científico e tecnológico sólido. Ela apresenta uma adequada distribuição de papéis entre atores públicos e privados, nesse campo, e um setor empresarial acostumado ao desafio da inovação e disposto a fazer investimentos crescentes em P\&D\&I. No entanto, sobretudo nos últimos anos, a Alemanha parece reconhecer, através de inúmeras medidas e programas, a necessidade de ações integradas e abrangentes para dar conta do desafio da inovação, compreendido de forma complexa e diferenciada.
O Brasil apresenta uma realidade marcada pelos contrastes. A escolarização da população é precária, mas o desenvolvimento da pós-graduação assegura ao país uma posição importante no cenário das nações produtoras de conhecimento científico e tecnológico. O sucesso na produção acadêmica de conhecimentos é acompanhado, por sua vez, de inexpressiva produção de patentes. $\mathrm{O}$ setor empresarial privado é responsável por fracos investimentos em P,D\&I. O Estado garante os níveis de investimentos mais significativos nesse campo. A experiência mais bem sucedida de inovação com impacto econômico deu-se no campo do agronegócio, com forte investimento público e intensa apropriação dos resultados pelo setor privado. Nesse cenário, chama a atenção o fato de que as políticas recentes de estímulo à inovação no Brasil parecem um conjunto de medidas avulsas, pouco integradas e refletem uma visão ainda estreita do problema a ser enfrentado.

(Recebido para publicação em 01 de setembro de 2011) (Aceito em 15 de dezembro de 2011)

\section{REFERÊNCIAS}

ANDIFES. Associação Nacional dos Dirigentes das Instituições Federais de Ensino Superior. Relatório de acompanhamento do programa de apoio a planos de reestruturação e expansão das universidades federais (REUNI). Brasília, 2010.

BALBACHEVSKY, Elizabeth. Processos decisórios em política científica, tecnológica e de inovação no Brasil: nova geração da política de ciência, tecnologia e inovação. Brasília: CGEE-MCT, 2010.

BECK, Urich. Sociedade de risco. Rio de Janeiro: Editora $34,2010$.

BERGEN COMMUNIQUÉ, 2005. Disponível em: www.ond.vlaanderen.be/hogeronderwijs/ bologna/ documents/MDC/050520_Bergen_Communique.pdf. Acesso em: 17 maio 2011.

BERLIN COMMUNIQUÉ, 2003. Disponível em: www.ond.vlaanderen.be/hogeronderwijs/ bologna/ documents/MDC/Berlin Communique1.pdf. Acesso em: 17 maio 2011

BMBF. Bundesministerium für Bildung und Forschung. Bildung und forschung die hightech-strategie für deutschland. Bonn,Al: 2006.

Bundesministerium für Bildung und Forschung. Bildung und Forschung. In: ZAHLEN 2011: Ausgewählte Fakten aus dem Daten-Portal des BMBF. Bundesministerium fur Bildung und Forschung. Referat Statistik, Internationale Vergleichsanalysen, Bonn,Al: 2011. 
Clarissa Eckert Baeta Neves, Fabrício Monteiro Neves

Bundesministerium für Bildung und Forschung. Bundesbericht forschung und innovation 2010. Bonn: 2010.

Bundesministerium für Bildung und Forschung Hochschulpackt 2020. Bonn: 2010a.

Bundes Ministerium für Bildung und Forschung. Disponível em: http://www.bmbf.de/ Acesso em: 11 maio 2011.

Bundes Ministerium für Bildung und Forschung. Bundesbericht Forschung und innovation 2010b. Disponível em: www.bmbf.de/ Acesso em: 15 abr.2011.

BOLOGNA DECLARATION, 1999. Disponível em: www.ond.vlaanderen.be/hogeronderwijs/ bologna/ documents/MDC/BOLOGNA_DECLARATION1.pdf. Acesso em: 12 abr. 2011.

BOTELHO, A. J. J.; BUENO, J. A. P. Financiando as relações entre a universidade e a indústria na América Latina: um apoio às universidade ou estímulo à inovação? In: SCHWARTZMAN, S. (Org.) Universidades e desenvolvimento na América Latina: experiências exitosas de centros de pesquisas. Rio de Janeiro: Centro Edelstein de Pesquisas Sociais, 2008 p.95-132. On-line

BRÄNDLE, Tobias. 10 Jahre Bologna Prozess. VS Research. Wiesbaden: 2010

BRASIL. Ministério da Ciência e Tecnologia. Plano plurianual do Ministério da Ciência e Tecnologia. Brasília, 2000.

MCT/CNPq. Programa institutos do milênio documento básico. Brasília, 2001.

MCT. Livro branco: ciência, tecnologia e inovação. Brasília: 2002.

MCT. Plano estratégico. Brasília, 2004.

MCT. Plano de ação de ciência, tecnologia e inovação para o desenvolvimento nacional. Brasília, 2007.

MCT/CNPq. Programa Institutos Nacionais de CET. Brasília, 2008, 2010. Documento de orientação.

MCT/CNPq. Plano de ação ciência, tecnologia e inovação para o desenvolvimento nacional (Pacti 20072010). Brasília, 2011.

BUDAPEST-WIENNA DECLARATION, 2010. Disponível em: www.ond.vlaanderen.be/ hogeronderwijs/bologna/ 2010 conference/ Acesso em: 08 jun. 2011.

CAPES/MEC. Coordenação de Aperfeicoamento de Pessoal de Nivel Superior. Estatísticas In: GEOCAPES. Disponível em: http://geocapes.capes.gov.br/ Acesso em: 10 maio 2011

DUTTA, S.; BENAVENTE, D. Measuring innovation potential and results: the best performing economies. In:

(Ed.) The global innovation index 2011.

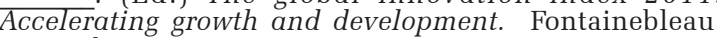
France by INSEAD, 2011. p.3-56.

ERICHSEN, Hans Uwe. Tendências europeias na graduacão e na garantia da qualidade. Sociologias, Porto Alegre, UFRGS, IFCH, v. 9, n.17, p.22-49, jan./jun. 2007.

ETZKOWITZ, Henry. Innovation in innovation: the triple helix of university-industry-government relations. Social Science Information,London, Sage, v.42, n.3, 2003

LEYDESDORFF, Loet. The dynamics of innovation' from national Systems and 'mode 2' to a triple helix of university-industry-government relations. Reserch Policy, New York, n.29, p.109-123, 2000.

FRAUNHOFER GESELLSCHAFT 2004: Deutschland innovativ. Impulse zur Stärkung der Innovationskraft. Fraunhofer Gesellschaft, press release, Date: 26/04/2004. Download from: Fraunhofer Gesellschaft (http:// www.fraunhofer.de/ fhg/press/pi).
GIBBONS, Michael et al. The new production of knowledge: the dynamics of science and research in contemporary societies. London: Sage, 1994.

GII. Global Innovation Index 2011. Accelerating Growth and Development. Fontainebleau: France by INSEAD, 2011.

HIGHTECH STRATEGIE. Ideen. Innovation. Wachstum. Hightech Strategie 2020 für Deutschland. Bonn, 2006.

HRK. Hochschulrektorenkonferenz. Statistische Daten zur Einführung von Bachelor- Masterstudiengängen Wintersemester 2010/2011. Statistiken zur Hochschulpolitik. Bonn, 2010. Disponível em: w w w. h r k.d e/d e/d o w n l o a d / d a t e i e n / HRK StatistikBA_MA_WiSe_2010_11_final.pdf Acesso em: $\overline{1} 2$ maio $201 \overline{1}$.

2010 Disponível em: www.hrk.de/de/home/ home.php Acesso em: 11 abr. 2011

Bologna Zentrum. 2010a. Disponível em: www.hrk-bologna.de/bologna/de/ index.php Acesso em: 15 jan. 2011

HOWALDT, Jürgen; SCHWARZ, Michael. Social innovation: concepts, research fields and international trends. Dortmund, 2010. IMO-International Monitoring. Disponível em: www.internationalmonitoring.com.

LONDON COMMUNIQUÉ. 2007. Disponível em: www.ond.vlaanderen.be/ hogeronderwijs/bologna/ documents/MDC/London Communique18May2007.pdf Acesso em: 12 jan 2011.

LUHMANN; Niklas. Sistemas sociales: lineamientos para una teoria general. Barcelona: Anthropos; México: Universidade Iberoamericana; Santafé de Bogotá: CEJA, 1998

$$
\text { La sociedad de la sociedad. México: }
$$
Iberoamericana; Herder, 2007.

Introdución a la teoría de sistemas. México D. F.: Antrhopos, 1996.

MEC/INEP. Instituto Nacional de Estudos e Pesquisa Educacionais Anísio Teixeira/Ministério da Educação. Sinopse da educação superior 2009. Brasília: INEP/Ministério da Educação. Disponível em: www.inep.gov.br/superior/censosuperior Acesso em: 26 abr. 2011.

MINISTRY OF SCIENCE, TECHNOLOGY AND INNOVATION. The framework of qualifications for the European Higher Education Area. 2005. Disponível em www.ond.vlaanderen.be/ hogeronderwijs/bologna/ documents/QF-EHEA-May2005.pdf Acesso em: 18 jan. 2011.

MOREIRA, Bruno et al. Onde está a inovação no Brasil? Belo Horizonte: Instituto de Inovação, 2007. Disponivel em: http:/inventta.net/radar-inovacao/categoria/artigosestudos/ Acesso em: 16 maio 2011

NEVES, Marcelo. Entre Têmis e o Leviatã: uma relação difícil: o Estado Democrático de Direito a partir e além de Luhmann e Habermas. São Paulo: Martins Fontes, 2006.

NEVES, Clarissa Baeta; KOPPE, Leonardo Renner. Processo de Bolonha: a reforma do sistema de Educacão Superior Europeu. Revista Tomo: revista do Núcleo de PósGraduação e Pesquisa em Ciências Sociais/Universidade Federal de Sergipe. São Cristóvão-SE, NPPCS/UFS, n.15, p.15-39, jul./dez., 2009a.

NEVES, Fabrício Monteiro. Novas configurações na produção do conhecimento. A dinâmica das modernas biotecnologias na periferia do sistema mundial de ciência e tecnologia. Civitas: revista de Ciências Sociais, Porto Alegre, PUCRS, v. 9, n.2, maio/ago. 2009.

NEVES, Clarissa Baeta. Reforma e desafios da educação superior: o processo de Bolonha dez anos depois. Sociologia \& Antropologia: revista do Programa de Pós-Graduação 
em Sociologia e Antropologia, Rio de Janeiro, UFRJ, v.1, n.1, jul. 2011

OECD; EC. Oslo Manual: guidelines for collecting and interpreting innovation. 3.ed. Paris: OECD and Eurostat, 2005.

ECD; EC/JRC. European Commission. Joint Research Centre. Handbook on constructing composite indicators methodology and user guide, by Nardo, M. M. Saisana, A Saltelli and S. Tarantola (EC/JRC), A. Hoffman and E. Giovannini (OECD), OECD publication Code: 302008251E1. 2008.

OECD. The OECD Innovation strategy: getting a Head Start on Tomorrow. Paris: OECD, 2010a. OCDE. Ministerial Report on the OECD Innovation Strategy: Key Findings. May 2010b, available at www.oecd.org/ dataoecd/ 51/28/45326349.pdf.

OLIVEIRA, Renato et al. Inovação tecnológica no Brasil: questões éticas da ação social em uma economia semiperiférica. Parcerias estratégicas, Brasília, n.29, 2009.

PRAGUE COMMUNIQUÉ, 2001. Disponível em www.ond.vlaanderen.be/hogeronderwijs/ bologna/ documents/MDC/PRAGUE_COMMUNIQUÉ pdf. Acesso em: 12.05.2011.

SCHWARTZMAN, Simon. Pesquisa universitária e inovação no Brasil In: Avaliação de políticas de ciência, tecnologia e inovação: diálogo entre experiências internacionais e brasileiras. Brasília: Centro de Gestão e Estudos Estratégicos, 2008. p.19-44.

SORBONNE JOINT DECLARATION. 1998. Disponível em: www.ond.vlaanderen.be/ hogeronderwijs/bologna/ documents/MDC/SORBONNE DECLARATION1.pdf Acesso em: 11 abr. 2011.
STICHWEH, Rudolf. Globalisierung von Wirtschaft und Wissenschaft produktion und transfer wissenschaftlichen Wissens in zwei Funktionsystemen der modernen Gesellschaft. [S.1.], 2000.

TEUBNER, Gunther. Direito, sistema e policontextualidade. Piracicaba: Ed. UNIMEP, 2005.

VIOTTI, Eduardo Baumgratz. Brasil: de política de C\&T para política de inovação? Evolução e desafios das políticas brasileiras de ciência, tecnologia e inovação. In: AVALIAÇãO de políticas de ciência, tecnologia e inovação: diálogo entre experiências internacionais e brasileiras. Brasília: Centro de Gestão e Estudos Estratégicos, 2008.p. 137 -174.

\section{FONTES INTERNET}

http://www.mct.gov.br/index.php/content/view/740.html http://www.mct.gov.br/index.php/content/view/723.html http://www.portalinovacao.mct.gov.br/pi/\#/pi/ conteudo\$MzI5

http://www.portalinovacao.mct.gov.br/pi/\#/pi

http://www.hightech-strategie.de/de/77.php, acessado em 22.04 .2011

http://www.cgee.org.br

http://geocapes.capes.gov.br/ 
Clarissa Eckert Baeta Neves,

Fabrício Monteiro Neves

\section{RESEARCH AND INNOVATION: new challenges for higher education in Brazil and in Germany}

\author{
Clarissa Eckert Baeta Neves \\ Fabrício Monteiro Neves
}

The article analysis the dynamics of institutional transformations of which universities in Brazil and Germany are going though in order to take up strategic roles in a social, political and economical context, characterized by the dynamics of innovation. Reforms in the higher education system, as well as projects and institutional strategies are objects of analysis on this piece of work. Germany has been going through a intense reform process of its higher education with the implantation of the project Bolonha, in the field scientific research and technology production and in relation to the market with the implantation of the vigorous project of promotion and direction of the national academic research. In Brazil, historically there is a lot of resistance to changes. Predominates the model for higher education still not very diverse and with a low level of relationship with the industry and the market, however lately, there has been a increase on the support of transformation. Systematic and institutional reforms are analysed by the light of historical and social peculiarities of the relationships between universities society in both countries focusing more contemporary dynamics.

KEY WORDS: research and innovation, universities, knowledge, reform, policies.
RECHERCHE ET INNOVATION: les nouveaux défis de l'éducation supérieure au Brésil et en Allemagne

\author{
Clarissa Eckert Baeta Neves \\ Fabrício Monteiro Neves
}

L'article présente l'analyse de la dynamique des transformations institutionnelles au sein des universités, au Brésil et en Allemagne, afin de leur permettre d'assumer des rôles stratégiques dans un contexte politique, économique et social, caractérisé par la dynamique de l'innovation. Les réformes du sytème de l'enseignement supérieur ainsi que les projets et les stratégies institutionnelles font l'objet de cette recherche. Depuis l'implantation du projet "Bologne", l'Allemagne passe par un processus intense de réforme de l'enseignement supérieur. Les répercussions se font sentir dans le champ de la production scientifique et technologique ainsi que dans la relation avec le marché, grâce à l'implantation de projets solides de soutien et d'orientation de la recherche académique nationale. Le Brésil a une grande résistance historique aux changements. Ce qui prédomine, c'est encore un modèle d'enseignement supérieur peu diversifié et trop peu en relation avec l'industrie et le marché, même si de la part de ces derniers des initiatives de soutien en faveur de transformations se sont multipliées. Des réformes systémiques et institutionnelles sont analysées à la lumière des particularités historiques et sociales de relations existantes entre l'université et la société dans les deux pays. L'accent est mis tout particulièrement sur les dynamiques plus récentes.

Mots-CLÉs: recherche et innovation, université, connaissance, réforme, politiques.

Clarissa Eckert Baeta Neves - Doutora em Sociologia pela Universidade de Münster-Alemanha. Professora da Universidade Federal do Rio Grande do Sul. Pesquisadora CNPq. Coordenadora do Grupo de Estudos sobre Universidade/GEU/UFRGS. Membro da comissão editorial da Revista Sociologias (UFRGS) e do Comitê de Avaliação do CNPq. Tem produção científica destacada na área de Sociologia da Educação e Educação Superior pesquisando sobre os seguintes temas: acesso e eqüidade, políticas educacionais de inclusão social, financiamento e cost-sharing, estudos comparados de sistemas de educação superior e as transformações dos sistemas de educação superior na Europa. Publicações recentes: Reforma e desafios da educação superior: o processo de Bolonha dez anos depois. In: Sociologia\&Antropologia. Revista do Programa de Pós- Graduação em Sociologia e Antropologia. Rio de janeiro: Universidade Federal do Rio de Janeiro. v.1, n.1, jul. 2011, p.181-208; Processo de Bolonha: a reforma do sistema de educação superior europeu. In: Revista TOMO- Revista do Núcleo de PósGraduação e Pesquisa em Ciências Sociais. Universidade Federal de Sergipe. São Cristóvão-SE. n. 15 jul./dez., 2009. p. 15 a 39 (a publicação saiu em outubro de 2010).

Fabrício Monteiro Neves - Doutor em Sociologia pela Universidade Federal do Rio Grande do Sul. Professor da Universidade Federal de Santa Maria. Tem experiência na área de Sociologia da ciência e do conhecimento e teoria social com ênfase em teoria dos sistemas sociais, sociologia da inovação e da tecnologia. Atua principalmente nos seguintes temas: Produção do conhecimento na periferia, sistema social da ciência, sistemas de inovação, teoria social. Publicações recentes: Estudos sociais em ciência e tecnologia e suas distintas abordagens. Sociologias (UFRGS. Impresso), v. 13, p. 22-42, 2011; A diferenciação centro-periferia como estratégia teórica básica para observar a produção científica. Revista de Sociologia e Política (Online), v. 17, p. 241-254, 2009. 
